\title{
Editorial
}

\section{Marcus Kracht}

Published online: 19 November 2009

(C) Springer Science+Business Media B.V. 2009

With the beginning of this issue I am taking over as managing editor of JoLLI. Patrick Blackburn has been managing the journal since 2002, a long time indeed. He has done a superb service to all of us by turning JoLLI into a central institution for the community as well as for FoLLI. As a reader I can say that JoLLI is one of the few journals that I read cover to cover.

I realise that it is hard to improve on what Patrick has done. Still, I promise to try. I think for any journal it is vital that the contributions are both interesting and of high quality. As for JoLLI, my aim is that it appeals to all people who are interested in the interaction of language, logic and information. There are by now several meetings which focus on this kind of interdisciplinary research; I mention only ESSLLI, NASSLLI, and WoLLIC. I shall be attentive to the directions into which the field is moving and try to make JoLLI a platform for new ideas. As the interest in this field is now growing fast, more and more interesting research is being done. I hope to attract the best contributions for JoLLI. By keeping an eye on the developments and talking to others I hope that I can make JoLLI attractive to a wide audience.

But as important as the job of an editor may be, it cannot be done without the help of the readership. You as readers are in fact the biggest source of inspiration, first and foremost by writing contributions yourselves, in other words by being or becoming an author. In this respect I hope that many of you will consider JoLLI not only as a source of ideas of others, but as a platform to share your views and results with the community. I shall assist in whatever ways I can. What I promise then is no more and no less than to turn your contributions and ideas into a journal that we all (and many more) like to read.

\footnotetext{
M. Kracht $(\varangle)$

Fakultät für Linguistik und Literaturwissenschaften, Universität Bielefeld,

Postfach 1001 31, 33501 Bielefeld, Germany

e-mail: marcus.kracht@uni-bielefeld.de
} 